\title{
Marriage as the Medium of Exploitation in Wife by Bharati Mukherjee
}

\author{
A. Rajalakshmi, M.A.,M.Phil.,(Ph.D) ., Dr.K.M.Sumathi,M.A, Phd., \\ Assistant Professor in English, St.Antony's College of Arts \& Sciences (W) , Dindigul, India. \\ Assistant Professor in English, M.V.M.Govt. Arts College (W), Dindigu, India..
}

\begin{abstract}
This paper highlights marriage as the medium of exploitation in Bharati Mukherjee's Wife. Women are seen as indissoluble from the family and most functions assigned to family are indirectly assigned to women. The family places mammoth obligations on women's shoulders and contours on their place and rewards in the toil market their roles in local, national and international affairs. Marriages are rooted in the Indian tradition: they are arranged by the family, and the people concerned have no choice. Social anxiety and social convention lead to the failure of marriages but since divorce is not allowed, people still have to live with each other. As a consequence, the characters experience alienation, and the terrible pressure children are subjected to, generally has its roots in failed marriages. Let us take the case of women: they cannot find fulfillment in marriage. The modern woman lives in a society dominated by men and marriage recurrently brings annihilation of the wife's individual persona. The view embodied female cohort Amit Basu is no company for Dimple, they are mismatched. Mukherjee takes up the quandary of a wife's adjustments in her husband's home.
\end{abstract}

Keywords: Annihilation, anxiety, Indissoluble, mammoth, recurrently.

\section{Introduction}

Bharathi Mukherjee's heroines are intrepid and firm. They have the strong potentiality for compliance; they live in the dense land of actuality and accept the sour truth of their live. Dimple in Wife fails to stride the conduit or play the societal roles traditionally assigned to an Indian woman. She is a symbol of an emblematic, acquiescent Indian housewife who patiently abides all the plights afflicted on her by the male dominated society. In common India marriage is not merely a union of two individuals; it is a coming together of two families. But in western countries like America, a marriage is simply a contract between two individuals. In the Indian tradition marriage is glorified as a holy union of man and woman. It is the turning point and the beginning of a new way of life. However, in Mukherjee's novels all these ideas regarding marriage are shattered by her modern liberated women. Marriage can no longer hold them down. In India a woman's fate is decided very early in her life because the parents start discriminating between their male and female child from the very beginning. It is persistently hammered on the girl's consciousness that she has to move somewhere else so she must be docile and assimilative in every circumstances. Thus a woman starts a life of duality and conflict since her childhood. After marriage she is in the hands of new people that belong to an entirely new set up. Melancholy leads to gloominess and some who cannot cope with depression have nervous breakdown and this is what happens to Dimple. The novelist portrays modern educated and career oriented middle class married women who is receptive to the changing times and situations illuminating a incredible imminent into the female psyche. The message of the novelist is shrill and patent. Mismatched marriages will bring adversity to both, may even execute both husband and wife. If they don't die they will be shoddier than dead.

\subsection{Dimple, the Victim of Phallocentrism}

\section{Methodology}

Mukherjee,s novel Wife reveals the yarn of Dimple, a ostensibly tame young Bengali girl who is full of dreams about her married life and so she fervently and anxiously waits for marriage. She thinks that marriage is a blessing in camouflage. It will bring her sovereignty, kismet and glee. At last her father Mr. DasGupta married her daughter with Amit Basu, an engineer, by scouring matrimonial advertisements. Basu's house is not striking, so she does not feel easy there. She doesn't like Amit's mother and sister also. Her mother-in-law dislikes her name 'Dimple' and wants to call her 'Nandini'. Dimple Basu has always lived in an implausible world, a world which is created by herself. But when she brazen out the hard realities of life the naps of her imagination are clipped. Amit was not the man Dimple has imagined for her husband.

\subsection{Heart-wringing anguish}

Mukerjee delineates the delicate swings of mood the sea-saw moments of joy and despair, the fragments of feelings perceived and suppressed, the life of senses as well as the heart-wringing anguish of the 
protagonist Dimple, a house wife. The novel depicts the life of Dimple at the level of the silent and the comatose. A receptive and pragmatic dramatization of the married life of Dimple and her husband Amit, it portrays and inquisitive critical appraisal to which the institution of marriage has been subjected to in recent years.

In Mukherjee's world, the vision of 'marriage-as-prison' is not restricted to India. On the Indian side, the problems of marriage are also present but in a tragic form. Home is a prison to her and she feels at home in nature, so home is not a place of protection and love and security; all these roles are subverted. Marriage is one of the main social conventions in India, but hypocrisy is the key word which rules in her novels. Her aggravation is built up gradually by the circumstances. She resents being wife in the Basu family and rebels against wifedom in many ways.

One such way is here including a miscarriage by skipping herself free from her pregnancy, which she views as a Basu's chattels even in her womb. She aspires for self-recognition and dream fulfillment. But Basu behaves in a diverse way. He wants her to a conjugal and docile. So Dimple hates Basu and his behavior. He needs her only for sexual pestering. She feels it's a sort culpable. Finally in her mentally disconcert state, she kills Amit in an act of self-liberation and eventually commits suicide. The fundamental humanistic values which bind a man and woman into the bond of togetherness the fidelity and companionship are away from social world today.

Men take pride in having relationship before and after marriage but this thing they do not expect from their women. Amit is no company for Dimple, they are miss-matched. The fundamental humanistic values which bind a man and woman into the bond of togetherness the fidelity and companionship are away from social world today. Men take pride in having relationship before and after marriage but this thing they do not expect from their women. We find this thing in the relation between Dimple and Amit Kumar Basu in Wife.

\subsection{Traditional marriage}

The family in India does not consist only of husband, wife and their children but also uncles, aunts, cousins and grandsons. This system is called joint family or extended family system. Marriage is an important event to establish a family. It is an institution which admits men and women to family life. It is a stable relationship in which a man and a woman are socially permitted to have children implying the right to sexual relations.

The Indian women have been accepting their husbands with their flaws and trying to live up to their desires and demands by transforming and molding themselves. The chains of traditional marriage are heavy and the escape routes are not available to a wife, who often seeks consolation and refuge in obsessions, masochisms or mental slavery often leading to her physical decay and death. The social ethos which has been to the continuity of women suppression sees to it that unacknowledged martyrdom becomes a part of a housewife's existence. She is expected to subordinate her own needs to those of her family.

She is supposed to bear her exploitation and suffering with willing fortitude. But Dimple is fantasizing about marriage, not to an engineer, but to a neurosurgeon. She imagines it will bring her freedom, love, and a more desirable life. Life has so far been simply a rehearsal for real life, the kind of real life that comes with marriage; for marriage brings opportunities that single women are denied in Indian culture, and Dimple longs for those freedoms more than anything. Dimple worries that she is not fair or bosomy enough for marriage. She felt that Amit had no love for her because she didn't have the longish face of a learned woman.

"She groped for the right words, then remembering Ina and Milt, she pounced on an English word and trotted it out the way Ina had done on a more eventful day. 'You just aren't supportive, if you know what I mean.' 'You're nuts,' Amit retorted. But he took his notebook out of his pajama pocket and scribbled down a word. Dimple tried to sidle closer to him so she could make out what he had written. Could he be writing down her word, adding it to his list of words to show off in company? Revenge! Revenge!(p208)"

Dimple is by nature contemptible and docile. She seeks to please him and to save her marriage. She clings to the moments of response and communiqué. She is willing to accept her role as a traditional wife and does not seek anything outside marriage.

The novel deals with the struggle of a young, beautiful and daring Indian woman trapped by her brutal husband. She experiences in the hands of cruel and unjust male dominated society. Dimple, the heroine of the novel gets suffocating environment with her husband Amit Basu. He is a acquisitive person and he gives more importance to money and power than human feelings. For men like Amit, money is the most important thing in life and this love for money becomes the root cause of his severance from his wife.

Dimple feels:

"Money had been part of the texture of her relationship with Amit, an emotional, forceful ingredient of it, intimately tied to his self-esteem. Money was, after all a form of pride, even of violence.(p38)"

The woman has to sacrifice herself for the family. Tolerance, fostering, adjustment, self-sacrifice are the good virtues expected from a woman. Men are not bound to fulfill these expectations. 


\subsection{Marriage as the medium of exploitation}

Dimple's husband, Amit Kumar Basu, is eventually found in the papers; Dimple is not the Basu family's first choice. When the wedding is perfect, it is clear that the marriage will not be. The first of Dimple's series of disappointments comes in learning that Basu is a short Prince Charming rather than a tall one. And in general her marriage does not turn out to be what she has hoped and dreamed. Rather than blossoming by gaining a firmer identity as a married woman, she finds that with each day she becomes less enthused. She is isolated and grows more and more depressed when she staying at home. She is detached and begins to perplex her reality with television. She reacts to others passively, never actively engaging in socializing or housework. She sleeps nearly all day, cooks when necessary, and increasingly watches television and reads magazines while her husband repeatedly inquires what she does all day. Amit begins to become something of a distortion.

Dimple seems at all times absent, but there is violence beneath her passive exterior. Before they left Calcutta for America, Dimple had found herself pregnant. Unable to face motherhood, she jumped rope until she aborted her fetus. She imagines her own suicide regularly. Being found dead would grant her some form of identity. But once, when Amit sneaks up to embrace her, she lashes at him with a knife, reflecting how impulsive her nature can be when she responds instinctively to the uncontrollable fears she has of her environment. Wife ends climactically, with Dimple committing murder after all. She kills Amit by stabbing at the mole on his face, her realities so confused that she is not fully aware of her own actions. Again it is depicted like a dream. She is symbolically freed from the power Amit and their marriage had over her through this violent act and seems to hope to embrace such freedom since she believes women on television get away with murder. She chooses to kill Amit by stabbing at his mole and in vengeance she has sought Amit's much more identifiable facial feature as the target for her frustrations.

Indian culture cherishes a feeling among young girls that marriage is their door way to happiness. Parents often give little freedom to their daughters. Hence they yarn to taste the fruit of freedom after their marriage. Dimple believed that marriage would bring her freedom, cocktail parties on carpeted lawns, and fund- raising dinners for noble charities. Marriage would bring her love and excitement. Soon after getting married, Dimple comes closer to reality which shatters all her dreams. She has always lived in a fantastic world, a world which is created by Dimple. But when she confronts the hard realities of life the feathers of her imagination are clipped. She thinks that Amit is not the man of her dreams and he was not the man she has imagined for her husband.

On her first day in the New York apartment she felt like a star collapsing inwardly. She tries to convey her fears and forebodings to Amit but neither does he try to understand her nor is he capable of rising above a humdrum understanding. The two do not stay happily owing to their weak economic condition. For four months Amit does not get a job. She hates Amit as he fails to fulfill her dreams. He is not the man that she wants to marry.

"Marriage would bring her freedom, cocktail parties on carpeted lawns, fund-raising dinners for noble charities. Marriage would bring her love" (p3).

The woman has to sacrifice herself for the family. Tolerance, fostering, adjustment, self-sacrifice are the good virtues expected from a woman. Men are not bound to fulfill these expectations.

Dimple has fixed her heart on marrying a neurosurgeon, but her father is looking for engineers in the matrimonial advertisements. It is the feminine duty of a woman in a male dominated society to subjugate her feelings and desires to the will of her father. Thus she believes that marriage is a blessing in disguise which will bring her freedom, fortune and perfect happiness, things she is too subservient to ask for in her own family.

\subsection{Knack of communiqué}

Dimple looks forward to the role of a wife with the hope that casting herself in a new role which will help her in winning her freedom. But she was lonely. Her husband could not understand her feelings as a result of which she was torn from within. The art of communication between husband and wife is essential to marital happiness. There is hardly any communication between Dimple and Amit neither verbal nor emotional. An intellectually idealized and cultural husband like Amit, finds Dimple a square peg in a round hole. There develops disheartening silence between the husband and the wife. Amit's queries remain unanswered by Dimple for she is unable to find a word of response. Dimple's inner turmoil's are so tense and acute that words fail her desire for articulation. She is unable to speak her trouble out for she is a woman who faces the suffering of her life and the opposition of the milieu in the true spirit of ideal Hindu womanhood where obedience and loyalty has degenerated to the state of dogged subservience. Hence her life becomes chaotic.

This estrangement between Dimple and her husband reminds one of Anita Desai's Cry the Peacock where an ever widening gap in communication between Maya and her husband is felt throughout the novel. Their married life is punctuated all along by "matrimonial silences". This failure in communication develops a breach between the couple which widens day by day and ultimately ruins their relationship. He fails to 
understand Dimple. He believes providing material comforts alone will make her happy. Dimple experiences loneliness at every quarter of her life. It is beyond her understanding

Husband in Indian conservative society is treated as god, sheltering tree, provider and protector. Dimple rejects to be an object of sacrifice, a showpiece and a silent and subservient creature to her husband. She aspires to be loved and respected and does not want only to be provided and protected by her husband as is desired in the case of other women. So she differs from other women. The dejections and disappointments of unrequited selfhood, the illusions and pining of love and the yearnings for companionship make up the stream of Dimple's consciousness. Recalling the ions of her split self entangled in her memory, she creates a world of harmony, a world of fantasy, understanding, authentic selfhood and a composite self. Dimple is not totally a silent and mute sufferer.

Dimple in Wife however controls her feelings and thoughts and does not ask Amit even ones, when he leaves his job and does some other work. She does not want to hurt him in any way, and hence feels incessantly sad and disappointed inwardly. At such moments she is no better than an ordinary unlettered woman. Here the couple sinks into utter silence in a mood of frustration and depression, without talking to each other and without sharing their ideas. Dimple's review of her relationship with her husband points to an unhappy. To her, married life becomes unbearable and monotonous, as it moved in a fixed pattern.

The Indian society depicts woman as a symbol of sacrifice through the image of Devi, like Sita, Savitri, and Gandhari. A girl child in the Indian family is treated partially. The first preference is always given to a boy child. From her childhood a woman is taught to suppress her wills, desires. She is taught to become a good wife, mother, and daughter-in-law and so on. She has no identity her own. In the Indian society the honor of the family depends upon the behavior of their own.

\subsection{She is the queen, not the slave}

Mukherjee insists that calling woman the weaker sex is a libel. It is man's injustice to woman. If by strength is meant brute strength, then, indeed, is woman less brute than man. If by strength is meant moral power, then woman is immeasurably man's superior. She has to be the complement of man. The woman who knows and fulfils her duty realizes her dignified status. She is the queen, not the slave, of the household over which she presides. Man should learn to give place to woman and a country or community in which women are not honored cannot be considered as civilized.

The tale of girls belonging to middle class is different. They are sent to school and college and required to help senior ladies of the family in the kitchen and other household work in their free time more as a part of their training. They get romantic ideas about love and marriage, but have no clear- cut idea of the person, who they think, would be compatible with them or who they would like to marry. After their school or college education is over, begins the period of waiting for them (husbands). They wait till some boy from amongst the various boys her parents have sent the proposal of her marriage to says 'yes, I will marry her'. They feel happy to see relief in their parents' faces and feel happier if the boy happens to be fair and handsome, is well qualified and has a good well paid steady job.

Thus Mukherjee advocates independence and assertiveness in women by depicting her characters as survivors who successfully bear torment both physical and emotional and raise a voice against the brutalities and violence surrounding them. They tend to rebuke the male dominating Indian society which discourages selfreliance in women and urge women to build up their fragmented lives and express their affirmation. Mukherjee's female characters are living in a society where the independence had also inspired women who had decided to throw away their veil, which had covered all their mental abilities and accomplishments. They had decided to move out of the four walls and go into the world with a new confidence and determination. However they had to face a lot of hurdles, created not only by men but also by other women. There were a lot of actions and reactions.

Mukherjee who has given voice to women's feelings and problems in their fictions. They have expressed the feelings of women and their struggle for existence in society. Her novels chart the dramas of entrance into a new land, adapting to a new way of life, in personal, social and historical terms. Her depiction of women and their different relationships portrays the dominance of patriarchal practices in traditional society, as well as the forms of liberation and empowerment which are available to women in their situation. Their situations and the difficulties they face are also realistically portrayed. It was determined that the more virtuous women maintained a more stable home life.

Even today society is not ready to give an equal status to women. In the Indian patriarchal society women are treated as objects. Men never consider women's point of view, and dictate terms. They have done nothing with the expectations of women. Mukherjee shows that women have the capacity to determine their priorities for self discovery and still continue to weave the fabric of family harmony man always wants sacrifice from his woman. Loss of identity causes intense pain and agony in her. The pathetic story of Dimple states the situation of women in India. A woman is always expected to sacrifice for her husband, children and others. 


\section{Outcome}

Dimple realizes that women do have power, wielded in a devious way; because they are suppressed by their husbands, they revenge themselves on their sons and daughters. Dimple has more expectations from life because her father had made her feel special. Despite all the progressive ideas Dimple has, she is a role model of Indian married woman's mind. Dimple is not a revolutionary character but wants to be different from the regular housewife lifestyle. It baffled her to realize that she who had considered herself to be so independent, so intelligent, and so clever; she who had been so proud of her logical and rational thinking; she who had been all set out to reform Indian womanhood had fallen into the trap waiting for her. Dimple's attitude towards her husband and family life made to think that her married life is a loveless one to an extent which is the main cause for her to drift away from her husband. It is frustrating and depressing ordeal that Dimple has undergone.

It will be disgusting experience to live with a man who does not love the woman the way she expected him to do. This is a common experience for many women in the contemporary society. At the same time, these women encounter a social problem which is nothing but the brand they get from the society as deserted women. The society continues to be male-dominated and attitudes towards women continue to be the same. Tara realized that she had surrendered before Amit not for love as she had imagined. She had surrendered because she wanted to avoid conflict in order to show to the family that her marriage had been a success. So she had continued to lie and compromise shedding bits of herself along the way. In Wife, Dimple is lonely. The difference between outlook of Dimple and Amit is so marked that they fail repeatedly to understand each other. This greatly affects their marital life. It becomes more of a compromise than a relationship based on love or mutual understanding. She realizes that a natural and harmonious relationship does not exist between them. They are unable to express real and genuine feeling to each other.

Dimple is unable to speak her trouble out for she is a woman who faces the suffering of her life and the opposition of the milieu in the true spirit of ideal Hindu womanhood where obedience and loyalty has degenerated to the state of dogged subservience. Hence her life becomes chaotic and the temperamental incompatibility between Dimple and Amit accounts for their in communication and quizzical silence. Marriage subjugates and enslaves women and it leads her to aimless days indefinitely repeated, life that slips away gently toward death without questioning its purpose. Women pay for their happiness at the cost of their freedom and emphasized that such a sacrifice on the part of a woman is too high for anyone because the kind of selfcontentment, serenity and security that marriage offers woman drains her soul of its capacity for greatness.

\section{Conclusion}

Mukherjee's Wife is about women whose lives are clouded by shame and guilt caused by the actions of their spouses. It is about desertion by husbands and the strength the deserted wives gather to keep their families together. The good moments in life like sharing love, affection, joys and sorrows are shown to be small remedies for big disasters. She concludes that the change in the position of women in any society is a reliable index to social change in general. Dimple and Amit hardly spoke to each other of love and sex. Love- making for them was a silent and inarticulate affair. She is self- alienated. It releases her from emotional turmoil. Through the image of a woman crawling into a hole, Mukerjee describes the woeful plight of Dimple, unprotected and unshelled.

The novel doesn't depict Dimple's life as a totally dismal and hopeless struggle. It suggests hope and change for the better. Her heroines endeavor for self realization and finally take control over their destinies. Reared by women within a feminine world, their normal destiny is marriage, which still means particularly subordination to man; for masculine prestige is far from extinction, resting still upon solid economic and social functions.

[1] Mukherjee, Bharati, Wife (New Delhi: Penguin Books, 1990)

\section{References}

[2] Cry, the Peacock. Delhi: Orient Paperbacks, p.24

[3] Vandana Singh, "The Fictional World of Bharati Mukherjee": published by Prestige books NewDelhi

[4] Bharati Mukherjee's fiction a perspective by Sushma Tandon, published by Sarup \& Sons, New Delhi

[5] Carb, Alison B. - An Interview with Bharati Mukherjee. The Massachusetts Review 29.1 (1988/1989): 645-54.

[6] Bharati Mukherjee: Critical Perspectives. Ed. Emmanuel S. Nelson. New York: Garland, 1993. 181-95.

[7] Dhawan, R, K. The Fiction of Bharati Mukherjee: A critical Symposium. New Delhi,1996. 